\title{
BMJ Open Where children and adolescents drown in Queensland: a population-based study
}

\author{
Belinda A Wallis, ${ }^{1,2}$ Kerrianne Watt, ${ }^{1,3}$ Richard C Franklin, ${ }^{1,3,4}$ James W Nixon, ${ }^{1}$ \\ Roy M Kimble ${ }^{1,2}$
}

To cite: Wallis BA, Watt $\mathrm{K}$, Franklin RC, et al. Where children and adolescents drown in Queensland: a population-based study. BMJ Open 2015;5:e008959. doi:10.1136/bmjopen-2015008959

- Prepublication history for this paper is available online. To view these files please visit the journal online (http://dx.doi.org/10.1136/ bmjopen-2015-008959).

Received 3 June 2015 Revised 16 September 2015 Accepted 19 October 2015

\section{(a) CrossMark}

${ }^{1}$ Centre for Children's Burns \& Trauma Research, Queensland University Child Health Research Centre, Lady Cilento Children's Hospital, Brisbane, Queensland, Australia

${ }^{2}$ Dept of Paediatric Surgery, Urology, Burns \& Trauma, Lady Cilento Children's Hospital, Brisbane, Queensland, Australia ${ }^{3}$ College of Public Health, Medical and Veterinary Sciences, James Cook University, Townsville, Australia

${ }^{4}$ Royal Life Saving Society Australia, Townsville, Queensland, Australia

Correspondence to Belinda A Wallis; belinda. wallis@uqconnect.edu.au

\section{ABSTRACT}

Objective: This retrospective population-based study examined drowning location by the site of immersion for both fatal and non-fatal drowning events in Queensland. Drowning location is not routinely collected, and this study used data linkage to identify drowning sites. The resulting enhanced quality data quantify drowning incidence for specific locations by geographic region, age group and by severity for the first time.

Design: Linked data were accessed from the continuum of care (prehospital, emergency, hospital admission and death data) on fatal and non-fatal drowning episodes in children aged $0-19$ years in Queensland for the years 2002-2008 inclusive.

Results: Drowning locations ranked in order of overall incidence were pools, inland water, coastal water, baths and other man-made water hazards. Swimming pools produced the highest incidence rates $(7.31 / 100000)$ for overall drowning events and were more often privately owned pools and in affluent neighbourhoods. Toddlers $0-4$ years were most at risk around pools (23.94/100 000), and static water bodies such as dams and buckets - the fatality ratios were highest at these 2 locations for this age group. Children 5-14 years incurred the lowest incidence rates regardless of drowning location. Adolescents 15-19 years were more frequently involved in a drowning incident on the coast shoreline, followed by inland dynamic water bodies.

Conclusions: Linked data have resulted in the most comprehensive data collection on drowning location and severity to date for children in the state of Queensland. Most mortality and morbidity could have been prevented by improving water safety through engaged supervision around pools and bath time, and a heightened awareness of buckets and man-made water hazards around the farm home for young children. These data provide a different approach to inform prevention strategies.

\section{INTRODUCTION}

Approximately every three minutes somewhere in the world, a child aged between 0 and 19 years drowns. ${ }^{1}$ These young people account for almost half of the worldwide annual total deaths, and those under the age of 5 years are disproportionately affected. ${ }^{2} 3$

\section{Strengths and limitations of this study}

Data linkage with case notes provided enhanced detail on non-fatal drowning locations and contributing factors associated with the environment of those locations.

- Incidence related to drowning locations and the effects of age on rates are reported for the first time.

- A breakdown of pool ownership, static and dynamic water bodies, coastal waters, and geographic and socioeconomic information provides new perspectives for drowning locations to inform prevention strategies.

- Locations in order of incidence overall were pools, inland water, coastal water, baths and other man-made water hazards.

- Heightened supervision and prevention efforts directed at developmental prevention strategies for all static water hazards close to home are required to reduce the drowning burden for toddlers $0-4$ years who have the largest drowning burden, regardless of the location. Adolescents are more likely to have drowning incidents in coastal water or inland dynamic water.

These numbers are believed to be underestimated by $39-50 \%$ because drowning due to natural disasters, transport incidents and intentional drowning are not included. ${ }^{4}$ These data also do not provide a measure of morbidity associated with drowning survival, nor do they provide information about where the drowning occurred. ${ }^{5}$ Current data from Queensland for children $0-19$ years established a fatal rate of 1.5/100 000, yet the non-fatal drowning rate was $13.6 / 100000 \mathrm{pa}^{6}$ For every fatality 10 other children were retrieved from the water and sought medical assistance. ${ }^{6}$

The circumstances leading to drowning can vary widely, and drowning location, age of the child and the child's activity are inevitably linked. ${ }^{7-10}$ Differences in geographical and cultural factors between highincome countries (HIC) and low-income and middle-income countries also exist. ${ }^{10}{ }^{11}$ In HIC, among children up to the age of 1 year, most drowning deaths occur in 


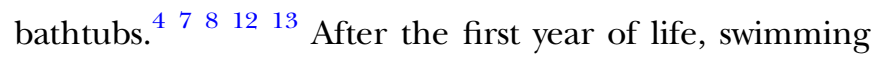
pools and man-made ponds (dams) or reservoirs are more frequently involved. ${ }^{4} 14{ }^{15}$ The WHO recognised that poor quality drowning data have contributed to a neglect of drowning as an important public health issue, and that if prevention strategies are to be successful, they need to be tailored to the local context. ${ }^{4}$ This emphasises the importance of good quality local data such as this which identifies drowning locations.

Currently, administrative data bases worldwide collect drowning information according to the International Classification of Diseases (ICD-10) ${ }^{16}$ at only three locations: baths (W65-66), pools (W67-68), bathtubs and natural water (W69-70). All other drowning locations are grouped under 'specified' or 'unspecified' (W73-74), which hinders injury prevention. Presently, there is no international aquatic standard for the classification of water body types which makes comparisons of locations and contributing factors almost impossible between countries. In this study, water type has been analysed as five categories to produce data and encourage prevention strategies that may be useful to other countries.

A further challenge to comprehending drowning is the difficulty in obtaining an accurate measure of actual exposure to water. By this we mean using a child-risk measure; that is, children who are likely to access, enter or be near water, rather than children from within a population-based group (some of whom may not necessarily be exposed to water). ${ }^{17}$ An Australian study demonstrated that when explored by actual exposure, drowning risk was underestimated and was higher than road traffic risk. ${ }^{18}$ This exposure measure reflects temporal fluctuations, lifestyle and regional characteristics; however, obtaining such data is usually done by telephone survey, is labour-intensive, expensive and logistically only possible in HIC.

Since the seminal work of Pearn and Nixon, ${ }^{19}$ and Pitt and Balanda ${ }^{20}$ exposed unfenced backyard swimming pools and bathtubs as high-risk locations, ${ }^{12} 2122$ the 04 -year old pool immersion rate trebled in Brisbane to 70.2 in $1986,{ }^{23}$ and then reduced to 20.7 in $2002 .^{24}$ Therefore, this is a timely detailed review that encompasses all locations (eg, pools, dams, bathtubs, creeks and rivers) and an exploration of any contributing factors in the chain of events leading to drowning. These data assist in an understanding of drowning incidents for prevention efforts, which must take into account child developmental factors, the characteristics of the water body, and the physical and socioeconomic environments. 115

The overarching aims of this paper were to identify locations of drowning events in Queensland children and adolescents, and to quantify the magnitude of fatal and non-fatal drowning at particular sites. Prevention strategies can be adopted for identified drowning sites beyond ICD-10 coding and characteristics associated with reoccurring locations and particular age groups were explored where available. This study fills a crucial gap in reporting locational incidence rates (IRs) for Queensland children, and presents analyses of fatal and non-fatal drowning location data collected using data linkage. This method achieved the best possible case capture to report all drowning cases as defined internationally. ${ }^{25}{ }^{26}$ We report for the first time IRs for drowning locations which frequently reoccurred in Queensland, along with the severity of events and contributing factors for particular drowning environments.

\section{METHODS}

Data were obtained for all drowning episodes in Queensland where medical assistance was sought for children and adolescents aged 0-19 years inclusive, between 1 January 2002 and 31 December 2008. For simplicity of reading, we will refer to this entire age group as children rather than 'children and adolescents'. This paper describes all drowning events, and specific drowning groups (eg, those who died), as fatal drowning or nonfatal drowning, as per the internationally agreed definition, ${ }^{25} 26$ and respiratory impairment was considered to have occurred if medical assistance had been sought.

Data custodians, extraction criteria and linkage methods are described elsewhere. ${ }^{6}$ However, in summary, identified data were manually linked to create a comprehensive data set across the continuum of care. Cases were included once only if a patient appeared in any of the databases accessed (patient transfers between hospital facilities were excluded) and were categorised as prehospital or emergency department (ED) treatment, hospital admission or death. Additionally, cases were included if the patient died at the scene or subsequently without discharge from hospital. Briefly, data on age, gender, drowning location of event, geographical event location (Accessibility/Remoteness Index of Australia (ARIA) based on event postcode), event time and day of week were collected. Residential postcode was used to calculate Socioeconomic Index for Areas (SEIFA) and drowning event postcodes were used to determine Index of Relative Socioeconomic Advantage and Disadvantage (IRSAD) ${ }^{27}$

Data on non-fatal drowning locations were obtained from prehospital and ED case notes, Queensland Injury Surveillance Unit, or ICD-10 codes for hospitalised cases. These notes were also used to obtain information on other circumstances leading to the drowning event.

Descriptive analyses used six categories for drowning locations: (1) Swimming pools (referred to as pools) were considered to be any manufactured structure for swimming in public, private (including wading pools) and commercial spaces. Included in this group were spas where water is not emptied at the end of each use (as opposed to spa baths which are typically emptied after use). (2) Baths were nominated as such and included shower baths and laundry tubs where children were being bathed. (3) Coastal water included beach, surf and rip currents (where people enter the water 
from the shoreline) and has been separated from inland water when it was specifically nominated as such in the text. For the purposes of analyses, the coastal water category includes ocean and sea where entry to the water was from a boat or jetty, as the number of events were small $(6 \%)$. (4) Inland dynamic water included creeks, rivers, weirs, streams of water and flood water. (5) Inland static water is usually naturally occurring water bodies such as lakes; however, due to their size, water storage reservoirs (dams) are included as well as those categorised as 'inland water bodies' and 'large area of water' or 'still water' in the data. (6) Locations classified as 'other' included manufactured (or man-made) hazards around the home such as buckets, tanks, ornamental ponds, drains and culverts, or animal water storage (such as troughs or dips). These generally involve smaller quantities of water and have been referred to as 'other man-made water hazards'.

Private and public pool settings were classified by levels of access. Private settings were considered to be a domestic pool (or water body) for private use of the residents (included single and multidwelling pools, wading pools, and outdoor spas). Public pool settings were categorised on two levels of access: public restricted access: commercial/municipal operated (or developed) settings where access is restricted by opening or closing times, or to patrons who may have paid for holiday accommodation or to use the facility (eg, water theme parks, school pools, hotels, resorts, caravan or holiday parks); and public unrestricted access: where there is no fencing, or open and close times (eg, tidal pools constructed on the beach).

Drowning locations were further collapsed into four categories for the purpose of calculating IRs. Inland water includes static and dynamic water, and due to small numbers 'other man-made hazards' was grouped with missing. The drowning locations were stratified by Accessibility and Remoteness Index for Australia (ARIA) ${ }^{27}$ and severity (death, admission to hospital or not admitted).
Fatality ratios were the number of fatal events over the number of non-fatal events. Crude IRs were calculated for each calendar year, using population data from the Australian Bureau of Statistics ${ }^{28}$ and are expressed as 100000 per population. Descriptive analyses used data on all drowning events that occurred in Queensland, and IRs were calculated for events among Queensland residents only due to the lack of age-specific population data on non-Queensland residents (for the denominator). Calculation of IRs for fatal and non-fatal events was stratified by age, drowning location and severity. $\chi^{2}$ Test for trends over time were computed using Centers for Disease Control and Prevention Epi Info V.7.1.2.0. Relative risks (RR) and 95\% CIs were calculated using IBM SPSS Statistics for Windows, V.22.0. Armonk, New York, USA: IBM Corp released 2013. Descriptive analyses (primarily $\chi^{2}$ tests) were also conducted to determine whether there were variations in characteristics of drowning events. Fisher's exact test was used where assumptions of $\chi^{2}$ tests were violated.

Custodian approvals were granted from Royal Life Saving Society Australia, Commission for Children and Young People and Child Guardian, Queensland Ambulance Service.

\section{RESULTS \\ Descriptive drowning location analyses $\mathbf{0}-\mathbf{1 9}$ years}

A total of 1299 (120 fatal and 1179 non-fatal) drowning incidents among 0-19-year olds in Queensland occurred between January 2002 and December 2008. Drowning location could be identified for 1088 (84\%) drowning incidents. Differences in drowning location and age groups are shown in table $1\left(\chi^{2}=352.13, \mathrm{df}=8, \mathrm{p} \leq 0.001\right)$ and indicate that more than half $(59 \%)$ of all drowning occurred in pools, followed by inland water $(13.4 \%)$, baths and coastal waters (12.5\%, respectively), and other man-made water hazards $(2.5 \%)$. There were significant differences in drowning location by age group. The

Table 1 Drowning location for all drowning by age group, gender and fatality ratios $(n=1088)^{\star}$

\begin{tabular}{|c|c|c|c|c|c|}
\hline Location & $0-4$ years (\%) & $5-9$ years $(\%)$ & $10-19$ years $(\%)$ & All drowning (\%) & Fatality ratio† \\
\hline Pool & $489(67.5)$ & $94(69.1)$ & $60(26.6)$ & $643(59.1)$ & 0.09 \\
\hline Public & & & & 196 & \\
\hline Private & & & & $367 \ddagger$ & \\
\hline Inland water & $60(6.3)$ & $24(17.6)$ & $61(27.1)$ & $146(13.4)$ & 0.32 \\
\hline Static water & & & & 68 & 0.35 \\
\hline Dynamic water & & & & 78 & 0.30 \\
\hline Bath & $128(17.7)$ & $\mathrm{np}(2.2)$ & $5(2.2)$ & $136(12.5)$ & 0.09 \\
\hline Coastal & $22(3.0)$ & $15(11.0)$ & $97(43.1)$ & $136(12.5)$ & 0.10 \\
\hline Shoreline & & & & 127 & \\
\hline Offshore & & & & 9 & \\
\hline Other man-made water hazards & $25(3.5)$ & 0 & $2(8.8)$ & $27(2.5)$ & 0.69 \\
\hline
\end{tabular}

(\%) Within location.

Data on frequency of other man-made water hazards are presented in this table, but for analyses this category was collapsed into missing. ${ }^{*}$ Drowning location was not able to be identified for 211 drowning events $(16 \%)$.

†Fatality ratio=number of fatal events/number of non-fatal events.

¥Eighty pools were not able to be identified as public or private.

$\mathrm{np}$, Not publishable due to small numbers. 
0-4-year age group had the highest frequency of drowning with more than two-thirds of drowning events occurring in pools $(68 \%)$, and $18 \%$ in baths. For adolescents 10-19 years more drowning events occurred in coastal water, followed by inland water and pools. The highest fatality ratio (0.69) for 0-19 years was associated with other man-made water hazards, and a breakdown of these sites showed buckets as being most predominant $(32 \%)$. Inland water incurred the second highest fatality ratio (dams stand out in this group with a fatality ratio of 2.67), and pools and baths the lowest. Pools generated the lowest fatality ratio indicating that children were more likely to be rescued from a pool and survive the event than any other locations. Males were overrepresented in all sites except bathtubs $\left(\chi^{2}=13.21, \mathrm{df}=3\right.$, $\mathrm{p}=0.004)$. More males than females were involved in events in dynamic water was 1.9:1 rather than static water 1.4:1

Eighty-eight per cent of pools were identified as being operated for public or private use. The frequency of occurrence of particular drowning sites is presented in table 2, and the top three sites for each age group are ranked for fatal and non-fatal events. As in table 1, the majority of pool drowning events $(n=367,57 \%)$ occurred in privately owned pools and a further $161(25 \%)$ were in public (commercially operated) pools where access was restricted to patrons. There were no fatalities at public unrestricted access pools. Most children who got into difficulty in pools $(60 \%)$ were in the water rather having fallen in at the time of the incident. However, the inverse was true for $0-4$-year olds as they were most likely $(85 \%)$ to have fallen in $\left(\chi^{2}=15.88, \mathrm{df}=4, \mathrm{p}<0.01\right)$. There were 68 incidents that could be identified as inland static, and 78 as dynamic water incidents.

\section{Remoteness}

Figure 1 shows the proportion of drowning events that occurred at specific sites in the state of Queensland by remoteness (ARIA). Pools were the most frequent drowning location for all geographic regions, with the majority occurring in major cities $(33 \%)$, regional $(24 \%)$ and remote $\left(2 \% ; \chi^{2}=28.23, \mathrm{df}=6, \mathrm{p}<0.001\right)$. All other drowning occurred at sites in similar proportions across the geographic regions.

\section{Socioeconomic status}

Drowning locations varied between areas in the highest $50 \%$ of IRSAD (decile $6-10$ indicating a relative advantage) compared with those in the lower $50 \%$ (decile $1-5$ indicating relative disadvantage; $\chi^{2}=22.61, \mathrm{df}=3, \mathrm{p}<0.001$ ). The highest frequency drowning locations in most advantaged areas were pools $(64 \%)$, followed by baths (13\%) and coastal waters $(12 \%)$. In areas with a relative lack of advantage twice as many drowning events occurred in

Table 2 Leading fatal and non-fatal drowning locations by age group, Queensland 2002-2008

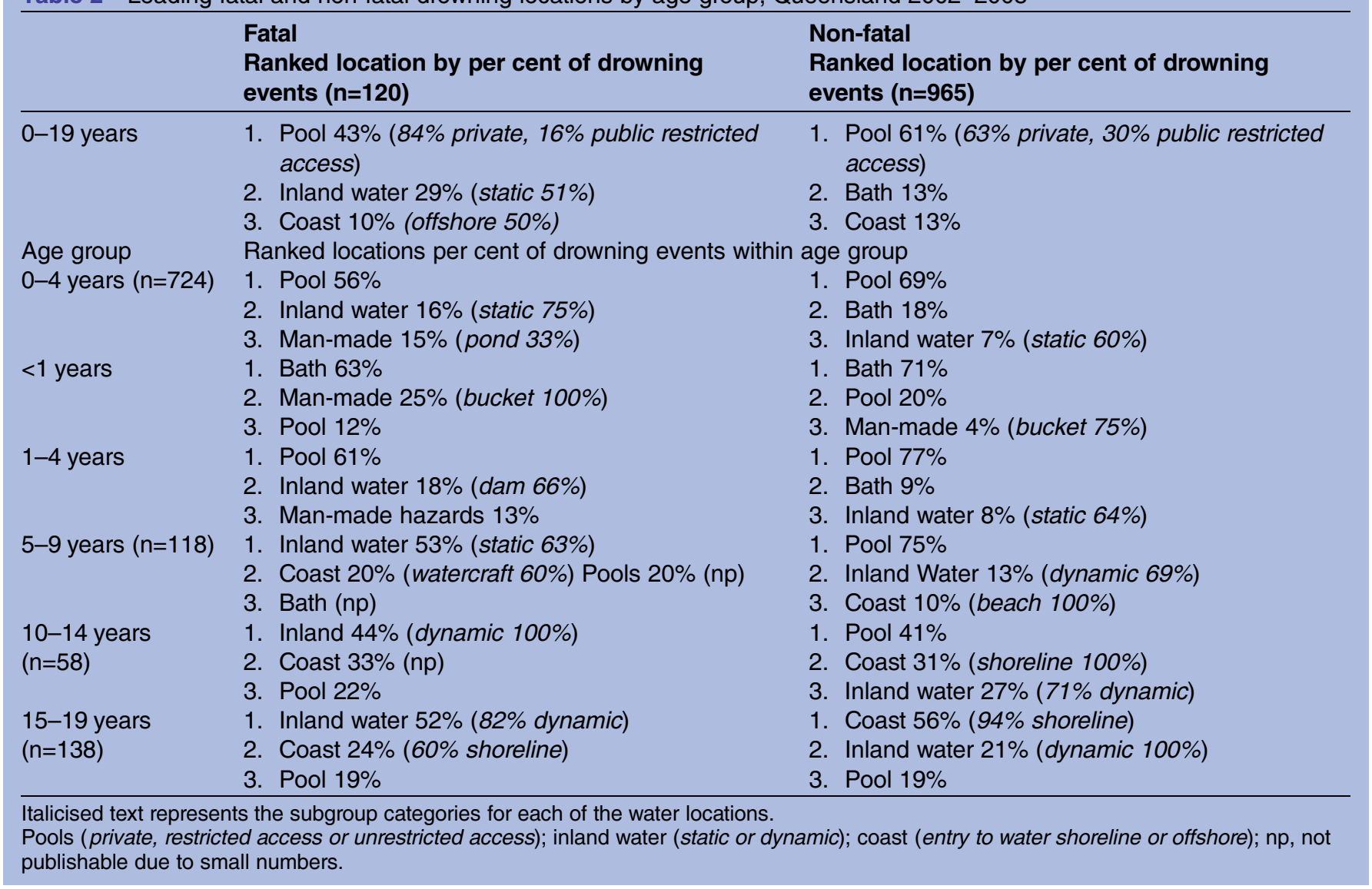




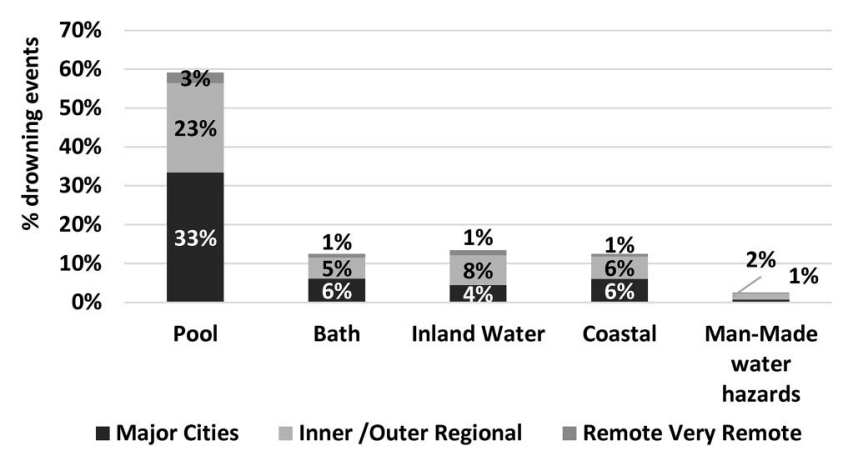

Figure 1 Drowning location by remoteness $(A R I A)^{\star}$ of geographic location of event, Queensland 2002-2008 ( $n=1088$ ). *ARIA (Accessibility/Remoteness Index of Australia) utilised postcode of the location of the drowning event. Data on man-made water hazards presented in this figure but for analyses this category was collapsed into missing.

inland water (22\% vs $11 \%$ ) and other man-made hazards (4\% vs $2 \%$ ) than areas of advantage. Disadvantaged areas also incurred higher proportions of fatal drowning events than disadvantaged areas (14\% vs $7 \%$ ), and higher proportions of fatal drowning events compared with nonfatal events $\left(43 \%\right.$ vs $\left.28 \% ; \chi^{2}=14.717, \mathrm{df}=1, \mathrm{p}<0.001\right)$.

\section{Overall drowning location IRs $\mathbf{0}-19$ years}

There were 1179 Queensland residents involved in drowning events and 981 (83\%) where a drowning location was identified (figure 2).

Overall, the highest drowning IRs for 0-19-year olds over the study period were in pools. This was followed by inland water, coastal water, baths and man-made water hazards.

\section{Trends over time}

Pools had the highest IRs for all types of drowning events (table 3). Total drowning rates (fatal and nonfatal combined) for 0-19-year olds significantly increased over the study period for pools $(69 \%)$, inland water $(67 \%)$ and in coastal waters $(63 \%)$, whereas there were small (non-significant) decreases in rates for bath and man-made water locations. Non-fatal drowning events were a significant proportion of these increases-pools $(87 \%)$, inland water $(85 \%)$ and the coast $(63 \%)$. There were no significant changes over time in fatal rates for any location.

\section{Gender}

The male-to-female ratio for all drowning events where location could be identified was $1.5: 1$ which varied by location $\left(\chi^{2}=13.21, \mathrm{df}=3, \mathrm{p}=0.004\right)$. Males had a greater risk of drowning than females at any location, but particularly pools and inland water. The only exception was baths where a risk of drowning was $22 \%$ lower in males than females though this was not significant $(R R=0.78$, 0.56 to 1.10$)$.

\section{Location by age group and severity}

Trends over time

There were no significant changes over the 7 years in fatal rates at any of the locations in any age group. Where total IRs increased this was primarily due to increases in non-fatal drowning events (table 4). Pool drowning rates increased over time in every age group except for those aged less than 12 months; however, the increases were significant in children $0-4,1-4$ and 5-9 years. Increased rates were seen in inland water drowning for 10-14-year non-fatal drowning, and coastal drowning in 5-9-year olds. For children over 2 years, bath drowning is a rare event. The highest percentage $(74 \%)$ of unknown locations was in the 0-4-year age group.

Analyses for the separate locations stratified by age and severity are shown in figure 3 and table 5 . Information on contributing factors where they were able to be identified is presented in the following text.

\section{Pool drowning}

Swimming pools (figure 3) incurred high drowning rates in the 1-4-year age group for fatalities, admissions and non-admissions than any of the other age groups. The highest rates of pool drowning occurred in children aged 1, 2 and 3 years for total drowning events, hospital admissions and fatal events. Two-year olds were the most vulnerable in terms of risk of pool drowning ( $\mathrm{IR}=37.34)$.
Figure 2 Total drowning incidence rates by drowning location, Queensland residents 0-19 years, 2002-2008 (IR, incidence rate).

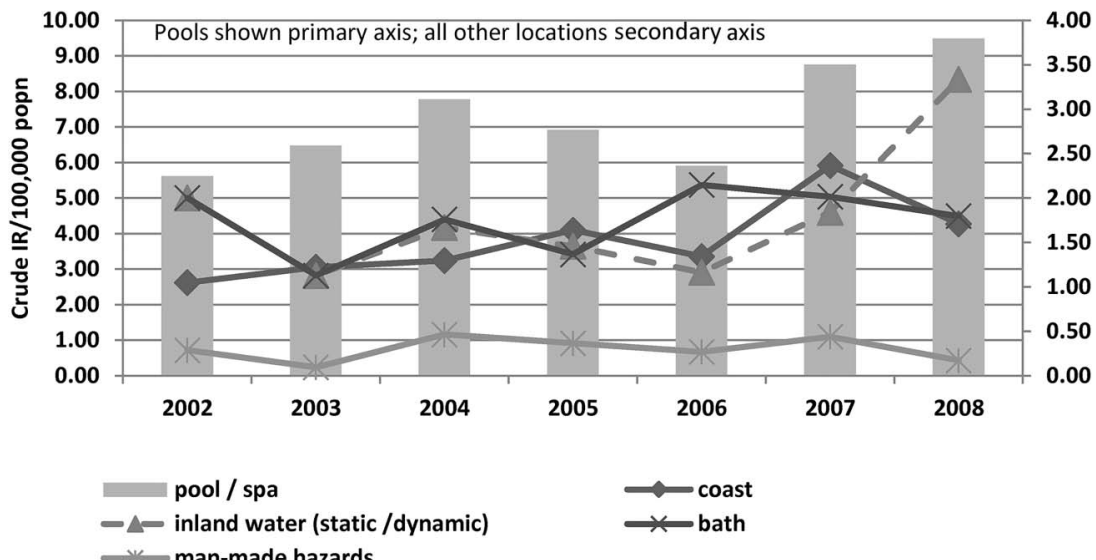

$\because$ man-made hazards 
Table 3 Drowning IRs by location, severity and gender, Queensland residents 0-19 years, 2002-2008

\begin{tabular}{|c|c|c|c|c|c|c|c|}
\hline & \multirow[b]{2}{*}{ Fatal } & \multirow[b]{2}{*}{ Admitted } & \multirow[b]{2}{*}{ Not admitted $†$} & \multirow[b]{2}{*}{ Total } & \multicolumn{3}{|c|}{ Fatal and non-fatal IR } \\
\hline & & & & & Female & Male & RR (95\% Cl)‡ \\
\hline Pool & 0.65 & 5.04 & 1.63 & $7.31^{\star \star \star} \uparrow$ & 5.76 & 8.74 & $1.52(1.28$ to 1.80$)$ \\
\hline Inland water & 0.45 & 0.97 & 0.39 & $1.81^{\star *} \uparrow$ & 1.41 & 2.25 & $1.60(1.14$ to 2.24$)$ \\
\hline Bath & 0.14 & 1.14 & 0.47 & $1.75 \downarrow$ & 1.97 & 1.54 & $0.78(0.56$ to 1.10$)$ \\
\hline Coastal & 0.13 & 0.56 & 0.84 & $1.53^{\star} \uparrow$ & 1.41 & 2.25 & $1.04(0.72$ to 1.50$)$ \\
\hline Other man-made water & 0.13 & 0.09 & 0.08 & $0.30 \downarrow$ & 0.21 & 0.38 & $1.78(0.76$ to 4.20$)$ \\
\hline
\end{tabular}

${ }^{*} p<0.05 ;{ }^{* *} p<0.01 ;{ }^{* *} p<0.001$; increases $(\uparrow)$; decreases $(\downarrow)$; or no change $(\leftarrow \rightarrow)$ in drowning incidence over time.

†Not Admitted=non-fatal cases that did not require hospitalisation but were treated in emergency department or attended by ambulance with no further treatment.

$\ddagger$ Reference category females.

$\mathrm{IR}$, incidence rate; $\mathrm{RR}$, relative risk.

\section{Inland water}

Fatal drowning occurred at this location across all age groups (figure 3); however, no infant $<1$ year fatally drowned in inland water bodies. Dams were the most common location in this category for the 1-4-year age group. Toddlers aged 1-4 years were 2.7 times more likely to drown than their counterparts aged 5-19 years in bodies of inland water (table 5). Admission rates for inland drowning were highest for $1-4$ years $(\mathrm{IR}=2.23)$ and $<1.0$ for all other ages.

\section{Bath drowning}

Bath drowning was more frequent and severe in children under 5 years (figure 3). The male-to-female ratio for bath drowning was the same for $<1$ and $2-4$ years, but the bath drowning rate was 1.1 times higher for females than males aged 1 year, and 7 times higher for females 5-19 years (compared with males; table 5). Ranked fourth in drowning locations overall, bath drowning incidence was the greatest for infants aged $0-1$ year. The risk of a bathtub drowning event for an infant aged $<1$ year is 143 times than that of children 5-19 years.

Examination of case notes showed that the majority $(67 \%)$ of bath drowning events occurred when there was no supervisor in the room (the child was knowingly left alone in the water even for a short time ranging from $1 \mathrm{~s}$ to $30 \mathrm{~min}$ ). Seven per cent were left with a sibling (aged between 3 and 5 years) where the sibling either did not respond to, or contributed to the drowning in some way, or alternatively alerted the parent (usually that the water was overflowing). A small percentage $(5 \%)$ was the result of a seizure or intentional harm. None of the 18 cases who had direct supervision were fatal and all but one were aged $<1$ year.

\section{Coastal drowning}

Fatalities from drowning at the coast were rare $(I R<1)$ but occurred in all age groups. There were no coastal drowning fatalities for infants aged less than 1 year (figure 3). Drowning in coastal waters incurred the lowest total drowning rates for all children aged 0-19 years. Admission rates were highest for $1-4$ years, and were $<1.0$ for all other age brackets. Almost half of fatal coastal events were related to offshore watercraft, swimming alone or at night, or in rough unpatrolled surf. Almost half of all fatal offshore watercraft victims were not wearing a life jacket. Risk of a coastal drowning event was $16 \%$ lower in younger children 1-4 years than older children 5-19 years, but this was not significant ( $95 \%$ CI 0.52 to 1.35 ; table 5 ).

\section{Other man-made water hazards}

This category had the lowest numbers of drowning events of all, yet the highest proportion of fatalities $(41 \%)$ (data not shown due to small numbers). All fatalities occurred among $0-4$ years. There were no

Table 4 Trends over time in drowning location incidence rates by severity and age, Queensland, 2002-2008

\begin{tabular}{|c|c|c|c|c|c|c|c|c|}
\hline \multirow[b]{2}{*}{ Age years } & \multicolumn{2}{|c|}{ Pool $(n=565)$} & \multicolumn{2}{|c|}{ Bath $(n=135)$} & \multicolumn{2}{|c|}{$\begin{array}{l}\text { Inland water } \\
(n=140)\end{array}$} & \multicolumn{2}{|c|}{ Coast $(n=118)$} \\
\hline & Non-fatal & Total & Non-fatal & Total & Non-fatal & Total & Non-fatal & Total \\
\hline $0-4$ & $21.68^{\star \star} \uparrow$ & $23.94^{*} \uparrow$ & 6.36 & $6.85 \downarrow$ & 2.48 & $3.18 \uparrow$ & 0.80 & $1.13 \uparrow$ \\
\hline$<1$ & 4.55 & $4.81 \downarrow$ & 18.19 & $19.53 \downarrow$ & 1.07 & $1.07 \downarrow$ & $\mathrm{np}$ & $\mathrm{np}$ \\
\hline $1-4$ & $26.01^{\star *} \uparrow$ & $28.78^{*} \uparrow$ & 3.38 & $3.65 \downarrow$ & 2.84 & $3.72 \uparrow$ & 1.28 & $1.35 \uparrow$ \\
\hline $5-9$ & $3.40^{\star \star} \uparrow$ & $3.55^{* *} \uparrow$ & 0.10 & $0.16 \leftrightarrow$ & 0.78 & $1.20 \uparrow$ & $0.47^{\star} \uparrow$ & $0.63^{*} \uparrow$ \\
\hline $10-14$ & 1.51 & $1.56 \uparrow$ & $\mathrm{np}$ & $\mathrm{np}$ & $1.00^{\star * \star} \uparrow$ & $1.20 \uparrow$ & 1.15 & $1.30 \uparrow$ \\
\hline 15-19 & 0.87 & $1.07 \uparrow$ & 0.15 & $0.20 \uparrow$ & 1.17 & $1.68 \uparrow$ & 2.75 & $2.90 \leftrightarrow$ \\
\hline
\end{tabular}

${ }^{*} \mathrm{p}<0.05 ;{ }^{* *} \mathrm{p}<0.01 ;{ }^{* * *} \mathrm{p}<0.001$ increases $(\uparrow)$; decreases $(\downarrow)$; or no change $(\leftarrow \rightarrow)$ in drowning incidence over time; trends only shown for total drowning or where significant; $\mathrm{np}$, not publishable due to small numbers being potentially identifiable. 

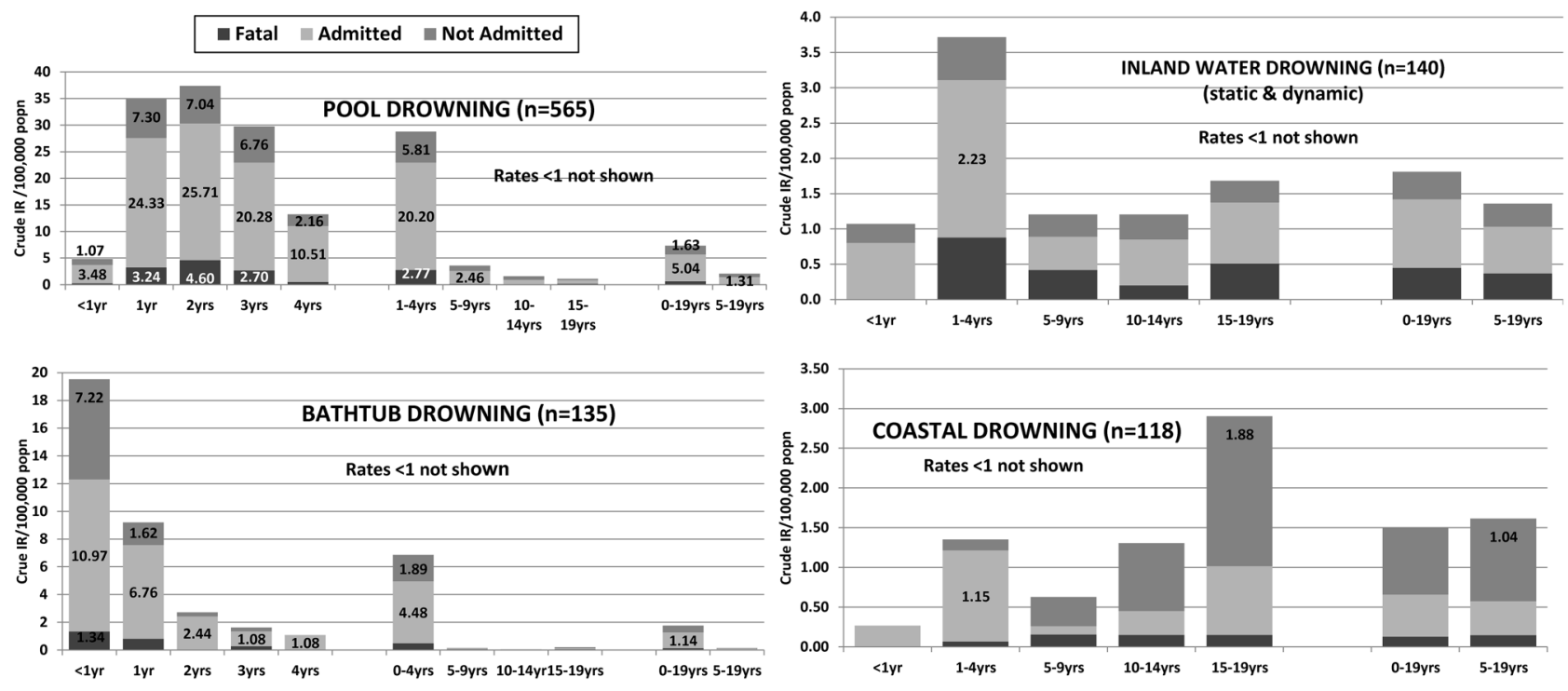

Figure 3 Drowning locations incidence rates by severity and age, Queensland, 2002-2008 (IR, incidence rate).

drowning events (fatal or non-fatal) in 5-9 years, or 1014 years and non-fatal events were rare in 15-19 years. Incidence was highest in children aged 0-4 years $(\mathrm{IR}=3.18)$ and $96 \%$ of all cases were in this age group. Admission rates for $<1$ and $1-4$ years were approximately equal $(\mathrm{IR}=0.53$ and $\mathrm{IR}=0.54)$. The majority of these locations involved static water, and buckets were the most common drowning danger (33\%). Hazards such as ornamental ponds, tanks, stock troughs and stock dips presented the greatest risks for toddler drowning especially for those under 1 year $(\mathrm{IR}=1.34)$, and the risk of drowning in such water hazards was 78 times that of older children $5-19$ years $(\mathrm{RR}=78.50,95 \%$ CI 9.171 to 671.90). Males were twice as likely as females to drown in these types of water bodies, but this was not significant.

Table 5 Drowning location IRs and RR of any drowning event by severity, stratified by year of age, Queensland, 2002-2008

\begin{tabular}{|c|c|c|c|c|c|}
\hline $\begin{array}{l}\text { Age } \\
\text { (years) }\end{array}$ & $\begin{array}{l}\text { IR total } \\
\text { drowning }\end{array}$ & $\begin{array}{l}\text { RR } † \text { of drowning event } \\
\text { compared with } \\
5-19 \text { years }(95 \% \mathrm{Cl})\end{array}$ & $\begin{array}{l}\text { RR } \dagger \text { of hospital admission } \\
\text { after drowning compared with } \\
5-19 \text { years }(95 \% \mathrm{Cl})\end{array}$ & $\begin{array}{l}\text { RR } ¥ \text { of fatal drowning } \\
\text { compared with non-fatal } \\
\text { drowning }(95 \% \mathrm{Cl})\end{array}$ & $\begin{array}{l}\text { M:F } \\
\text { ratio } \\
\end{array}$ \\
\hline \multicolumn{6}{|c|}{ Pool drowning (public and private)) } \\
\hline$<1$ & 4.81 & 2.36 (1.44 to 3.87$)$ & 2.65 (1.47 to 4.77$)$ & $0.59(0.01$ to 044$)$ & $1: 1.7$ \\
\hline 1 & 34.88 & 17.07 (13.31 to 21.88$)$ & 18.55 (13.68 to 25.15$)$ & 0.10 (0.06 to 0.019$)$ & $1.4: 1$ \\
\hline 2 & 37.34 & 18.26 (14.30 to 23.32$)$ & 19.60 (14.51 to 26.48$)$ & $0.14(0.09$ to 0.23$)$ & $1.7: 1$ \\
\hline 3 & 29.74 & $14.55(11.23$ to 18.84$)$ & $15.46(11.25$ to 21.24$)$ & $0.10(0.05$ to 0.19$)$ & $2.1: 1$ \\
\hline 4 & 13.20 & $6.46(4.63$ to 9.00$)$ & 8.01 (5.45 to 11.77$)$ & $0.04(0.01$ to 0.18$)$ & 1.8:1 \\
\hline $1-4$ & 28.78 & $29.12(22.14$ to 38.31$)$ & $15.40(11.99$ to 19.78$)$ & $0.11(0.08$ to 0.15$)$ & $1.6: 1$ \\
\hline $5-9$ & 2.04 & 1 & 1 & $0.7(0.04$ to 0.15$)$ & $1.7: 1$ \\
\hline \multicolumn{6}{|c|}{ Inland water (static and dynamic) } \\
\hline$<1$ year & 1.07 & $0.78(0.29$ to 2.14$)$ & $0.92(0.28$ to 2.97$)$ & & $\mathrm{np}$ \\
\hline $1-4$ years & 3.72 & $2.73(1.93$ to 3.84$)$ & 3.35 (2.11 to 5.33$)$ & $0.31(0.17$ to 0.58$)$ & $1.5: 1$ \\
\hline $0-4$ & 3.18 & 2.34 (1.67 to 3.27$)$ & 2.92 (1.86 to 4.60$)$ & $\mathrm{np}$ & 1.6:1 \\
\hline $5-19$ & 1.36 & 1 & 1 & $0.38(0.23$ to 0.62$)$ & $1.2: 1$ \\
\hline \multicolumn{6}{|c|}{ Bath drowning } \\
\hline$<1$ & 19.53 & 143.26 (69.04 to 297.26$)$ & $128.74(50.17$ to 325.78$)$ & 0.07 (0.03 to 0.18$)$ & $1: 1$ \\
\hline 1 & 9.19 & 67.45 (31.23 to 145.70$)$ & 79.35 (30.38 to 207.28$)$ & 0.10 (0.03 to 0.32$)$ & $1: 1.3$ \\
\hline $2-4$ & - & 13.21 (5.82 to 30.0029 . & $17.97(6.63$ to 48.71$)$ & 0.05 (0.01 to 0.39$)$ & $1: 1$ \\
\hline $0-4$ & 6.85 & 50.25 (24.60 to 102.67$)$ & 52.55 (21.31 to 129.57$)$ & $0.08(0.4$ to 0.15$)$ & $1: 1.1$ \\
\hline $5-19$ & 0.14 & 1 & 1 & $0.33(0.07$ to 1.65$)$ & $1: 7$ \\
\hline \multicolumn{6}{|c|}{ Coastal drowning (shoreline and offshore) } \\
\hline $1-4$ & 1.35 & $0.84(0.52$ to 1.35$)$ & 8.81 (4.01 to 19.35$)$ & $0.05(0.01$ to 0.40$)$ & $1: 1$ \\
\hline $5-19$ & 1.62 & 1 & 1 & $0.33(0.07$ to 1.65$)$ & 1.3:1 \\
\hline
\end{tabular}

$\mathrm{F}$, female; IR, incidence rates quoted per 100000 population per annum; $\mathrm{M}$, male; $\mathrm{np}$, not publishable due to small numbers; RRt, relative risk reference group 5-19 years; RR , relative risk reference group fatal (non-fatal is any drowning event-prehospital and admitted). 


\section{DISCUSSION}

Drowning locations ranked in order of overall incidence were pools, inland water, coastal water, baths and lastly other man-made water hazards. The magnitude of drowning at these sites was much greater in Queensland than previously reported for the rest of Australia or the USA. ${ }^{29-32}$

Previous research indicates that young children aged 0-4 years had a sevenfold risk of a drowning event over $5-19$-year olds, ${ }^{6}$ signifying that the high risks for drowning associated with the early developmental years need to be examined in the context of pools, baths and inland water-particularly water storage dams and other man-made water hazards close to the home. Mortality case series have previously provided the only data on hazardous locations such as dams or buckets, ${ }^{33} 34-37$ whereas, these detailed locations provide insights for national hospitalisation data, ${ }^{32}$ which lack location details beyond ICD-10 coding of pools, baths and natural water. Coding for more than one-quarter of the $0-4$-year cohort was 'unspecified' and yet this age group constitutes $43 \%$ of the total all-age drowning hospitalisation in Australia. ${ }^{32}$ The details contained in this nonfatal data point to locations around the home that are not unique to Queensland, and are eminently preventable at a national level with appropriate interventions.

The discussion which follows is presented in the context of location (or water type), the predominant age of the child affected and any prevalent contributing factors. The results reinforce the necessity for better drowning location definitions (an aquatic standard) for the classification of water body types in coded data enabling prevention strategies to be targeted by drowning location as well as geographic regions. Such multilevel approaches can target an appropriate audience for the age group at risk, and promote specific interventions observed to have promising outcomes. ${ }^{10} 3839$

\section{Pools}

Overall, more than half of all Queensland child drowning occurred in pools and predominantly among males. Encouraging signs of fatality prevention are that the swimming pool fatality rate is much lower than reported in $1976(\mathrm{IR}=0.65$ vs $\mathrm{IR}=22.55),{ }^{40}$ and pools incurred the lowest fatality ratio of all sites. However, the highest admission rates, and significant increases in non-fatal pool drowning rates over the reporting period, along with higher rates than previously reported in 1976 $(\mathrm{IR}=9.49$ vs $\mathrm{IR}=6.2),{ }^{40}$ indicate the potential for morbidity and further fatalities ${ }^{10}$ and highlight that there is no room for complacency if this significant burden is to be reduced. Pool drowning occurs predominantly in privately owned pools, which are more often than not located in areas of relative high socioeconomic advantage. It occurs more often in the city, but also in inner and outer regional areas as well as remote areas across Queensland.
Pool density has been shown to affect drowning, ${ }^{20} 4142$ although the methods to calculate it differ between pools/population-at-risk and pools/number of dwellings. An estimate of $311000^{\mathrm{i}}$ pools and spas registered in Queensland homes ${ }^{43}$ per 1660750 dwellings ${ }^{44}$ gives density ratio of 1:5 which is similar to an earlier Brisbane City study. ${ }^{20}$ To some extent this high density of pools would explain the over-representation of this location in drowning episodes; however, this higher exposure will also require consolidation of political will and public acceptance for ever-strengthening interventions to be implemented. The Queensland Pool Registry (operating since 2010) is anticipated to not only confirm the number of pools in Queensland, but also verify the presence of pool fencing which complies with current legislation. More importantly, with an ageing stock of pools in Queensland, ensuring that fences and self-closing gates are maintained and operating is a priority. ${ }^{45}$

It is equally important to prevent young children from getting into the pool alone, but also to protect them while they are in the water. The majority of children got into difficulty while they were known to be in or around water; however, 0-4-year olds were most likely to have fallen in. Pool fencing was mandated in Queensland in 1991 and has been shown to be an effective drowning countermeasure for such lapses in supervision of young children. ${ }^{20} 46$ Over the long term, pool fatality in this age group has reduced in Queensland and this has been linked to everstrengthening legislation implementing standards related to pool fencing. ${ }^{47}$ Regulatory control by individual local councils from 1992 led to inconsistencies in enforcement, so it is difficult to say definitively that this has reduced fatality on its own; however, as the only intervention promoted consistently over the time, this is a positive sign towards reducing drowning in this age group.

Obligatory cardiopulmonary resuscitation (CPR) courses for all registered pool owners could provide an opportunity to append other pool safety information about pool toys and flotation devices; and the necessity for close, constant and visual supervision. ${ }^{49} 50$ This is particularly critical for the vulnerable ages $1-3$ years. In this study, dimensions of supervision ranged from 'direct' (constant visual where physical proximity to the child allowed a quick response) to 'indirect' supervision (where the supervisor knows the child is in or near water but is unable to take immediate protective action) ${ }^{51}$ Common risk factors were reliance on siblings as caregivers, or a misguided belief that carers would hear if trouble occurred. In the majority of these lapses (over 64\%) caregivers knowingly left the child in or near water for just a short time to tend to laundry, food preparation or the phone.

The older age groups incurred the least pool immersions and it is not clear why they were involved in fewer

${ }^{\mathrm{i}}$ (G Hemmings, A/Principal Advisor DLGP, personal email communication, March 28, 2012). 
events, but may be related to better swim ability, some level of supervision and/or a developing concept of water safety. Nonetheless, this was the location with the highest frequency for 5-9-year olds, leaving no room for complacency.

\section{Inland water}

Ranked second as a drowning location overall, this was the leading location for fatalities in children 5-19 years. In younger children 1-4 years, more than half $(55 \%)$ of drowning locations were dams with an overwhelming fatality ratio of 2.66. In rural settings a safe fenced house yard/play area is the best way to prevent young children from wandering alone long distances ${ }^{33}$ to water hazards that they may have visited regularly. For adolescents 1019 years, these settings more often involved dynamic water and was more frequently chosen for recreation than pools. Inland water settings have been targeted nationally ${ }^{52}$ and this may go some way to reducing the significant increase in drowning at this type of location. Behaviour change interventions which tackle common risk factors such as over-estimating or under-estimating ability or current strength; swimming alone or at night, or after consuming alcohol. ${ }^{53}$ These kinds of water settings were more often found in areas of relative low socioeconomic advantage.

\section{Baths}

Hospital admission following a bath drowning was second only to pool drowning in children 0-19 years and may be related to the young age of most bath immersions. A further breakdown of ages within the 0 4-year group indicated engaged direct supervision as lacking in the bathroom for infants $<1$ year. Although bathtubs ranked as the fourth location in overall drowning, a very high risk was indicated for infants $<1$ year (143 times 5-19-year olds). Bathtub drowning interventions are best targeted at parents of very young children as immersions are unusual above 2 years. Parents and carers should be reminded to never leave young children alone in the bath (even for short periods) or in the care of a sibling. Baths were the sole location where significantly more females than males had drowning events. The other age group of concern for bath drowning is adolescents $15-19$ years where intent and the involvement of other substance use played a role.

\section{Coastal water}

Non-fatal drowning rates increased over the study period and the coastal shoreline was the second most frequent location for intervention activities for 5-9 years. Unfortunately, it is not always recorded if coastal drowning events were at beaches patrolled by lifeguards, albeit a sound drowning prevention intervention to address the significantly increasing burden. It is law that children 1-12 years require a life jacket when in small boats. ${ }^{55}$ Small watercraft incidents offshore resulting in fatality show that children not wearing life jackets can and do drown. Water recreation incidents for adolescents 15-19 years at the surf beach involved rip currents, exhaustion and alcohol. Interventions and risk factors suggested were similar for inland water drowning (see above).

\section{Other man-made water hazards}

These more unusual water bodies produced the highest fatality ratio and mostly occurred in children $0-4$ years $(96 \%)$. Strengthened efforts are required to educate new parents that buckets left partly filled after use resulted in one-third (32\%) of drowning events. They are a lesser known but universal threat ${ }^{35} 375657$ as are man-made water hazards such as troughs, in-ground tanks, and drains or culverts. There is scope to mitigate access at the time these water bodies are created. These were more common in areas of relatively low socioeconomics generally in line with more rural settings.

\section{Strengths and limitations}

This is the first study on drowning location to comprehensively utilise linked data across the continuum of care (prehospital to fatality), and effectively map the 'patient journey' from the moment of retrieval from the water to definitive care. Drowning is a process which is the outcome of a chain of events, ${ }^{58}$ and data that capture patterns within that chain of events have an inherent value. The value in collecting text narratives is validated by the previously unexplored magnitude of non-fatal drowning locations that frequently reoccur. Data linkage limitations have been published previously. $^{6}$

These linked data are a major strength of this study and allowed identification of detailed information on drowning location. A substantial proportion of data on drowning location were obtained from case notes prepared by paramedics who attended the scene, or text entered in the 'presenting complaint' field in the emergency department. This was true even for cases resulting in hospitalisation following the drowning event, as information on these events is limited by the available ICD-10 codes to the following categories: bathtub (W65-W66), swimming pool (W6-68), natural water (W69-70, with no differentiation between lake, open sea, river and stream); other specified drowning and submersion (W73); and unspecified drowning locations (W71, a very frequently occurring code indicating it is used as a dump code). Including the prehospital and emergency case notes allowed calculation of IRs and analyses at a much more detailed level than has previously published. The utility of the consequent linked data is great, and also allowed identification of factors that contributed to the drowning event such as supervision, swimming alone and other similar risk factors. Data on supervision and contributing factors were not analysed in detail in this paper but are planned for the future.

The authors acknowledge that coastal drowning events may be underestimated where it has been categorised as 
'large area of water' or 'natural water'. These, along with 'natural still water' have been categorised as inland static water. Age-specific population data used to calculate rates for immersion sites may underestimate risk of drowning; however, water exposure data ${ }^{18}$ and pool data ${ }^{42}$ were not available for Queensland. Further work is required in improving the collection and description of aquatic locations. It may be that some parents sought medical care for their children as a precautionary measure after the event, and this is noted when known.

In 2010, further legislation that postdates these data introduced a register in Queensland where pool owners are obligated to register their pools, and ensure pool fencing complies with Australian standards before sale or rental of the property. Owners who do not sell or rent had a 5-year window to ensure that their pool fencing complied. Certification requires updating every 2 years. The register utilises hospital presentation data, and any pool where a child had a drowning event and seeks medical assistance is investigated for contributing causes. We look forward to findings of these inspections to provide contributing factors to morbidity and improved fencing compliance. ${ }^{45}$

\section{CONCLUSION}

This is the first study in Australia to link data for drowning events and explore the differences between fatal and non-fatal drowning locations by incidence, age and severity. This enhanced quality data have identified target populations, socioeconomic groups, geographic regions along with contributing factors specifically related to drowning locations in Queensland. This is a different perspective to inform injury prevention strategies.

Swimming pools yielded the highest IRs for overall drowning events and pose the largest burden across all age groups. Swimming pools dominate the drowning burden for 0-4 years and produced the most fatalities, admissions and affect more age groups than any other location. Older children were more frequently involved in a drowning incident at the coast, followed by inland water bodies. Bath drowning requires intervention for infants less than 1 year. Swimming alone, or for young children, being in the water unsupervised even for a short time was the most prevalent contributing factor. Mortality and morbidity incidence will be reduced by ensuring engaged supervision around pools and at bath time, improved water safety barriers between the house and pools and dams; and a heightened awareness of buckets and man-made farm water hazards.

Twitter Follow Richard Franklin at @Franklin_R_C

Acknowledgements The authors thank the data custodians: Queensland Ambulance Service, Queensland Injury Surveillance Unit, Queensland Health, Mater Health Services, CCYPCG, Royal Life Saving Society Australia and National Coronial Information System. They also thank the Queensland Children's Medical Research Institute for a supportive research environment (This Institute was formerly located at Royal Children's Hospital and is now
The University of Queensland Child Health Research Centre located in the Lady Cilento Children's Hospital.)

Contributors BAW conceptualised and designed the study, carried out the analysis, drafted the initial manuscript and approved the final manuscript as submitted. KW assisted in the design of the study, carried out quality control of analysis, reviewed and revised the manuscript and approved the final manuscript submitted. JWN assisted in the design of the study and approved the final manuscript as submitted. RCF assisted in the design of the study, reviewed and revised the manuscript and approved the final manuscript. RMK assisted in conceptualisation of the study, reviewed and revised the manuscript and approved the final manuscript as submitted.

Funding Funded by Queensland Injury Prevention Council, QIPC 00.01/01. QIPC had no involvement in data collection, analyses, data interpretation, report writing or publication decision-making.

Competing interests None declared.

Ethics approval Ethics and approvals were sought and granted from Children's Health Services District (Royal Children's Hospital Human Research Ethics Committee HREC/09/QRCH/38; Royal Children's Hospital Institutional Approval; University of Queensland Medical Research Ethics Committee \#2009001463; Mater Health Services Human Research Ethics Committee \#1446E; and National Coronial Information System \#CF/07/13729 (20072010), \#CF/10/25057 (2010-2013), \#CF/13/19798 (2013-2016). Director General approval was granted through Public Health Application, Queensland Health 16/3/2010 Ref RD002254.

Provenance and peer review Not commissioned; externally peer reviewed.

Data sharing statement All the data are from the Queensland drowning study titled '7-year review of drowning in children and adolescents $0-19$ years, Queensland, 2002-2008', and were obtained from third party data custodians with strict ethical guidelines protecting privacy covered under legislation. Ethics committees, data custodians and approval from Director General under the Public Health Act all have specific conditions and requirements relating to access to these data which we cannot breach. Owing to the ethical restrictions, the data cannot be sent to a public repository. However, aggregate and non-identifiable data are provided in the tables, and requests for the original data can be sent to the data custodians. The contact details for each data custodian can be provided by contacting any of the following authors: Belinda Wallis b.wallis@uqconnect.edu.au; Kerrianne Watt Kerrianne.watt@jcu.edu.au; Richard Franklin Richard.franklin@jcu.edu.au.

Open Access This is an Open Access article distributed in accordance with the Creative Commons Attribution Non Commercial (CC BY-NC 4.0) license, which permits others to distribute, remix, adapt, build upon this work noncommercially, and license their derivative works on different terms, provided the original work is properly cited and the use is non-commercial. See: http:// creativecommons.org/licenses/by-nc/4.0/

\section{REFERENCES}

1. Peden M, Oyegbite K, Ozanne-Smith J, et al. World report on child injury prevention. Ch 3 Drowning. Geneva, Switzerland: World Health Organization and UNICEF, 2008.

2. Peden M, McGee K, Sharma G. The injury chart book: a graphical overview of the global burden of injuries. Geneva: WHO World Health Organisation, 2002.

3. WHO, World Health Organization. Drowning Fact Sheet No 347. WHO Violence and Injury Prevention Programme, 347. Geneva: World Health Organization, 2014 Geneva: World Health Organization, 2014

4. Meddings D, Hyder AA, Ozanne-Smith JE, et al. Global report on drowning: preventing a leading killer. World Health Organization, 2014:76.

5. WHO, World Health Organization. Global burden of disease 2004 update (disease and regional injury estimates for 2004). Geneva, Switzerland: World Health Organization, 2008.

6. Wallis BA, Watt K, Franklin RC, et al. Drowning mortality and morbidity rates in children and adolescents 0-19 yrs: a population-based study in Queensland, Australia. PLOS ONE 2015;10:e0117948. 
7. Brenner RA, Trumble AC, Smith GS, et al. Where children drown, United States, 1995. Pediatrics 2001;108:85-9.

8. Quan L, Cummings P. Characteristics of drowning by different age groups. Inj Prev 2003;9:163-8.

9. Rivara FP, Grossman DC, Cummings P. Injury prevention. Second of two parts. N Engl J Med 1997;337:613-18.

10. Wallis $\mathrm{BA}$, Watt $\mathrm{K}$, Franklin $\mathrm{RC}$, et al. Interventions associated with drowning prevention in children and adolescents: systematic literature review. Inj Prev 2015;21:195-204.

11. Hyder AA, Borse NN, Blum L, et al. Childhood drowning in low- and middle-income countries: urgent need for intervention trials. $J$ Paediatr Child Health 2008;44:221-7.

12. Pearn J, Nixon J. Bathtub immersion accidents involving children. Med J Aust 1977;1:211-13.

13. Sibert J, John N, Jenkins D, et al. Drowning of babies in bath seats: do they provide false reassurance? Child Care Health Dev 2005;31:255-9.

14. Sibert JR, Lyons RA, Smith BA, et al. Preventing deaths by drowning in children in the United Kingdom: have we made progress in 10 years? Population based incidence study. BMJ 2002;324:1070-1.

15. American Academy of Pediatrics. Technical report-prevention of drowning. Pediatrics 2010;126(1):e253-e62.

16. WHO, World Health Organization. ICD-10 International Statistical Classification of Diseases and Related Health Problems. Geneva: World Health Organization, 1992.

17. Cross, Canadian Red. Drownings and other water-related injuries in Canada 1991-2000. Module 1 (2003):21, p6.

18. Mitchell RJ, Williamson AM, Olivier J. Estimates of drowning morbidity and mortality adjusted for exposure to risk. Inj Prev 2010;16:261-6.

19. Pearn J, Nixon J. An analysis of the causes of freshwater immersion accidents involving children. Accid Anal Prev 1979;11:173-8.

20. Pitt W, Balanda K. Childhood drowning and near-drowning in Brisbane: the contribution of domestic pools. Med J Aust 1991;154:661-5.

21. Pearn J, Nixon J. Swimming pool immersion accidents: an analysis from the Brisbane Drowning Study. Med J Aust 1977a; $1: 432-7$

22. Pearn J, Nixon J. Are swimming pools becoming more dangerous? Med J Aust 1977;2:702-4.

23. Pitt WR. Increasing incidence of childhood immersion injury in Brisbane. Med J Aust 1986;144:683-5.

24. Edmond KM, Attia JR, Deste CA, et al. Drowning and near-drowning in Northern Territory children. Med J Aust 2001;175:605-8.

25. van Beeck EF, Branche CM, Szpilman D, et al. A new definition of drowning: towards documentation and prevention of a global public health problem. Bull World Health Organ 2005;83:853-6.

26. Idris AH, Berg RA, Bierens J, et al. Recommended guidelines for uniform reporting of data from drowning: the "Utstein style". Resuscitation 2003;59:45-57.

27. ABS, Australian Bureau of Statistics. 2033.0.55.001 Socioeconomic Index for Australia (SEIFA). Canberra: Australian Bureau of Statistics, 2008

28. ABS, Australian Bureau of Statistics. Australian Historical Population Statistics cat. no. 3105.0.65.001 TABLE 26 Population(a), age and sex, Qld, 1901 onwards. Canberra: Australian Bureau of Statistics, 2008.

29. CDC (Centers for Disease Control and Prevention). DrowningUnited States 2005-2009. MMWR (Morbidity and Mortality Weekly Report). Centers for Disease Control and Prevention, 2012.

30. AlHWPointer S. Trends in hospitalised injury, Australia, 1999-00 to 2010-11. Injury research and statistics series no 86 Cat no INJCAT 162. Canberra: AlHW, 2013

31. RLSSA, Royal Life Saving Association Australia. National Drowning Report 2013. Sydney: Royal Life Saving Society Australia, 2013.

32. AlHWPointer S, Helps Y. Trends in hospitalised injury, Australia, 1999-00 to 2010-11. Injury and Research and Statistics series No 86 INJCAT 162. Canberra: AIHW (Australian Institute of Health and Welfare), 2013

33. Bugeja L, Franklin R, Bugeja L, et al. Drowning deaths of zero- to five-year-old children in Victorian dams, 1989-2001. Aust J Rural Health 2005;13:300-8.

34. Byard RW, Lipsett J. Drowning deaths in toddlers and preambulatory children in South Australia. Am J Forensic Med Pathol 1999;20:328-32.
35. Cass DT, Ross FI, Grattan-Smith TM. Child drownings: a changing pattern.[see comment]. Med J Aust 1991;154:163-5.

36. Gardiner SD, Smeeton WM, Koelmeyer TD. Accidental drownings in Auckland children. N Z Med J 1985;98:579-82.

37. Mann NC, Weller SC, Rauchschwalbe R. Bucket-related drownings in the United States, 1984 through 1990. Pediatrics 1992;89(6 Pt 1):1068-71.

38. Cohen L, Swift S. The spectrum of prevention: developing a comprehensive approach to injury prevention. Inj Prev 1999;5:203-7.

39. Purnell M, McNoe B. Systematic review of drowning interventions and risk factors and international comparison of water safety policies and programs: report to the Accident Compensation Corporation. Injury Prevention Research Unit, University of Otago, Dunedin, 2008.

40. Pearn JH, Nixon JW, Wilkey I. Freshwater drowning and near-drowning accidents involving children: a five year population study. Med J Aust 1976;2:942-6.

41. Morgenstern H, Bingham T, Reza A. Effects of pool-fencing ordinances and other factors on childhood drowning in Los Angeles County, 1990-1995. Am J Public Health 2000;90:595-601.

42. Shenoi RP, Levine N, Jones JL, et al. Spatial analysis of paediatric swimming pool submersions by housing type. Inj Prev 2015;21:245-53.

43. Coroners Court (Coroner Spencer R). In the matter of an inquest in the cause and circumstances surrounding a drowning death. CAIR-COR No 00000037 of 2003. Queensland, 2005.

44. ABS (Australian Bureau of Statistics). Quick stats-Queensland (State) Census data for housing 2006 (accessed June 2014). Secondary Quick stats-Queensland (State) Census data for housing. 2006. http://www.censusdata.abs.gov.au/census_services/ getproduct/census/2006/quickstat/3?opendocument\&navpos=220 (accessed Jun 2014).

45. DHPW, Dept Housing and Public Works. Pool Safety Laws. http:// www.hpw.qld.gov.au/construction/BuildingPlumbing/PoolSafety/ PoolSafetyLaws/Pages/default.aspx (accessed Sep 2014). Secondary Pool Safety Laws. (accessed 21 Oct 2013).

46. Thompson DC, Rivara FP. Pool fencing for preventing drowning in children. Cochrane Database Syst Rev 2000;(2):CD001047.

47. QFCC, Queensland Family \& Child commission. Annual report: deaths of children and young people. Queensland, 2013-14. http:// www.qfcc.qld.gov.au/Documents/annual-report2014/ QFCC-AnnualReport2013-2014.pdf (accessed Jan 2015). ISSN: 1833-9522 (PRINT); 1833-9530 (ONLINE), 2014.

48. Quan L, Bennett EE, Branche CM. Interventions to prevent drowning. In: Doll LS, Bonzo SE, Mercy JA, Sleet DA, eds. Handbook of injury and violence prevention. New York, NY: Springer Science + Business Media, 2007:81-96.

49. Saluja G, Brenner R, Morrongiello BA, et al. The role of supervision in child injury risk: definition, conceptual and measurement issues. Inj Control Saf Promot 2004;11:17-22.

50. Petrass LA, Blitvich JD, Finch CF. Lack of caregiver supervision: a contributing factor in Australian unintentional child drowning deaths, 2000-2009. Med J Aust 2011;195:157.

51. Anderst J, Moffatt M. Adequate supervision for children and adolescents. Pediatr Ann 2014;43:e260-5.

52. Australian Water Safety Council. Australian water safety strategy 2016-20: towards a nation free from drowning (cumulative draft). Australian Water Safety Council, 2015:48.

53. Moran K. Will they sink or swim? New Zealand youth water safety knowledge and skills. Int $J$ Aquat Res Educ 2008;2:114-27.

54. Moran K, Quan L, Franklin R, et al. Where the evidence and expert opinion meet: a review of open-water: recreational safety messages. Int $J$ Aquat Res Educ 2011;5:251-70.

55. Government Q. Maritime Safety Queensland—Life Jacket Rules. Secondary Maritime Safety Queensland-Life Jacket Rules 17 April 2015. 2015. http://www.msq.qld.gov.au/Safety/Life-jackets.aspx

56. Jumbelic Ml, Chambliss M. Accidental toddler drowning in 5-gallon buckets.[see comment]. JAMA 1990;263:1952-3.

57. Kibel SM, Nagel FO, Myers J, et al. Childhood near-drowning-a 12-year retrospective review. S Afr Med J 1990;78:418-21.

58. McClure R, Stevenson M, McEvoy SE. The scientific basis of injury prevention and control. Melbourne: IP Communications Pty Ltd, 2004. 